\title{
Stressors and Coping Mechanisms of Pre-Service Teachers
}

\author{
Article by ${ }^{1}$ Joselito C. Gutierrez, ${ }^{2}$ Zandra B. Lid-ayan, ${ }^{3}$ Christine Joy M. Cuison, \\ ${ }^{4}$ Jezza B. De Vera, ${ }^{5}$ Vanessa B. Domingo, ${ }^{6}$ Clarence D. Dilem, ${ }^{7}$ James Mark B. \\ Diwag, ${ }^{8}$ Roy Rillera Marzo \\ 1,2,3,4,5,6,7 Saint Louis University-School of Teacher Education \\ Email: jo_guro_ako@yahoo.com,ZZan_Dhalrimph24@yahoo.com, \\ enitsirhcuison09@gmail.com deverrajezza@yahoo.com \\ vanessa_domingo28@yahoo.com clarence_alternative@yahoo.com \\ robjamesdiwag@yahoo.com \\ ${ }^{8}$ Deputy Dean, Asia Metropolitan University, Malaysia \\ Email: rrmtexas@yahoo.com
}

\begin{abstract}
It has been consistently testified that teaching as a profession prompted stress among teachers. It is essential that as early as practice teachers are being prepared to be licensed teachers, they need to be aware about the reality of teaching yet only few researches provide intensive information about the causes of the stressors of practice teachers. Since it is also the interest of this study to inform incoming practice teachers about the challenges that they might as well be encountering in the future, this study would be beneficial in providing them grounds to prepare themselves to combat possible stressors. Through the use of questionnaires and focus group discussion and by utilizing qualitative design, this study revealed workload, financial problem, cooperating teacher, call time, and students' misbehavior cause stress among practice teachers of the School of Teacher Education of Saint Louis University. They also identified counter measures they used in overcoming their stressors such as using personal coping strategies, behavioral coping strategies, and social coping strategies. It can then be drawn that even if practice teachers experienced a lot of stress, they still find ways to overcome their stressors.
\end{abstract}

Keywords: Practice teaching, pre-service education, practicum, stress

\section{Introduction}

Pre-service education often provides the first step in the professional development of teachers and this exposes practice teachers to new perspectives as well as prepares them in knowledge and skills (Wilke, 2004). Knowledge includes disciplinary content, or subject knowledge, and pedagogical content knowledge, or knowledge of how to teach. Pedagogical knowledge can be defined as the content, skills, and strategies required for effective teaching and pedagogical knowledge is linked closely to teacher belief in the perspective that there are factors that influence practice teachers' attitudes and beliefs toward the implementation of a variety of instructional models and strategies (Wilke, 2004; Gerges, 2001). Furthermore, pre-service education forms the basis for quality practice (Wilke, 2004). Ngidi et al., (2003) and Kiggundu et al., (2009) defined practice teaching as a period during which a student teacher is given an opportunity to do teaching trials in a school situation and are given the opportunity to apply theoretical knowledge acquired in lecture rooms to classroom teaching before actually getting into the real world of teaching. The study of McNay (2003) cited by Mapfumo et al. (2012) confirmed that practice teachers described practice teaching as the most worthwhile part of their program, and where they really learned to teach. Practice teaching is essential to future teachers because upon entering teacher education, practice teachers are expected to have already possessed 
well-developed set of beliefs (Joram \& Gabriele, 1998; Lonka, Joram \& Bryson, 1996; Anderson et al., 1995 cited by Chong et al., 2005). These beliefs and attitudes are constructed based on cultural and personal beliefs such as perceptions and expectations about what it takes to be an effective teacher and these are formed before practice teachers enter the program (Pajares, 1992 cited by Charlesworth et al., 1993).

While practice teachers are exposed to the reality of teaching profession, they are also subjected to the different difficulties that an in-service teacher could possibly encounter. It is inevitable that, along with the rewarding and satisfying aspects of the teaching practicum student teachers will also encounter a range of stressful experiences (Harvey, 1999). Stress contributes to health problems worldwide and its presence is felt in home, office, industry, and academic environments (Ekpenyong et al., 2013). Teaching has consistently been ranked as a high stress occupation (Griffith, Steptoe \& Cropley, 1999; McCormick, 1997 cited by Mapfumo et al., 2012) with between 33 and $37 \%$ of teachers studied regularly reporting being 'very/extremely' stressed due to factors intrinsic to the teaching profession (Chan \& Hui, 1995 cited by Chaplain, 2008). Because of the occupational stress in teaching, the attrition rate for teachers has reached alarming proportions in some parts of the world (Chaplain, 2008 \& Kyriacou et al., 2007). Student teachers have been reported to be vulnerable to stress because they enter a field in which the professional teachers are highly stressed (Wilhelm et al., 2000). Within the programs for the training of teachers, the most stressful component was Teaching Practice (MacDonald, 1993). According to Bowers et al., (1983) cited by Wadlington et al., (1998), practice teachers' stressors and anxieties are based from two areas of concern: classroom discipline and relationships. Specifically, relationships with students, cooperating teachers, and parents constructed the affective concerns, while subject knowledge, instructional strategies, and differentiated teaching constructed the instructional concerns and classroom discipline. Stress in general can be defined as the situation which occurs when a human being faces events perceived by them as dangerous, physically and psychologically (Atkinson et al., 1996 cited by Deniz (2006). Another definition of stress is taken from Altuntas (2003) cited by Deniz (2006) defining stress as frustrations brought about as the result of physical, mental and emotional burdens. Franks (1994) cited by Mapfumo et al., (2012) added that stress may involve selfdoubt, anxiety, fear and even anger accompanied by such physical symptoms as muscular tension, headaches and exhaustion.

Since practice teachers are prone to stress, they should be knowledgeable on how to handle this stress by identifying different coping mechanisms. Coping mechanism is the process of attempting to manage the demands created by stressful events (Bland, et al., 2012). Folkman and Lazarus (1987) believed that coping mechanism is all cognitive and behavioural efforts to master, reduce, or tolerate demands that cause an individual to be stressed. Similar perspective is taken from Harvey (1999) providing that the term coping strategies is used to describe the ways that practice teachers manage the events or situations they regarded as stressful. She added that knowledge of how students cope with practicum stresses would have the benefit of informing teacher education programs of the most effective ways of providing support. She highlighted that effective coping strategies have been found to ameliorate the effects of stress. Knowledge of how students cope with practicum stresses would have the benefit of informing teacher education programs of the most effective ways of providing support to future in-service teachers (Harvey et al., 2000). Kirton (2003) cited by Samms (2010) proposed some coping techniques such as instrumental coping focuses on ways to tackle the issue in order to reduce stress around a given situation, while emotional-focused coping gathers tools to nurture ones emotional health during the stressful period. Further, he defined active coping strategies involve an awareness of the stressor, followed by attempts to reduce the negative outcome. He proposed 
venting as an externalizing coping technique which is the outward expression of emotions, usually in the company of friends and family.

\section{Methodology}

\section{Research design}

This research study made use of the qualitative design to have a detailed description about the stressors and coping mechanisms of practice teachers. Questionnaires and focus group discussion were utilized to gather data.

\section{Sample}

The locale of this study is practice teachers who took their practice teaching and were enrolled in Saint Louis University-School of Teacher Education. The total population of practice teachers in the secondary level is 44 composed of 8 males and 36 females and 34 for the elementary level composed of 7 males and 27 females. Practice teachers started their practice teaching on August 19, 2014.

\section{Instrumentation}

The use of questionnaire and a focus group discussion were utilized to extract the responses of the practice teachers regarding the stressors and coping mechanisms. Focus group discussion was integrated to aid the questionnaire. The questionnaire was validated to test the effectiveness of the questions.

\section{Data collection procedure}

The researchers requested the practice teachers to answer the questionnaire considering the venue and their availability. Focus group discussion was integrated for further elaboration and validation of their answers.

\section{Ethical considerations}

After the validation of the questionnaire, a letter of permission addressed to the school dean to carry out the study was submitted to request practice teachers to answer the questionnaire. The availability of the respondents was noted before administering the questionnaire. The venue for the focus group discussion was made sure to be wide enough to contain the respondents to ensure their comfort.

\section{Data analysis}

The data gathered was analyzed through the use of qualitative design. Responses

were transcribed verbatim based on the focus group discussion and came up with different themes. 


\section{Findings and discussions}

\section{Stressors}

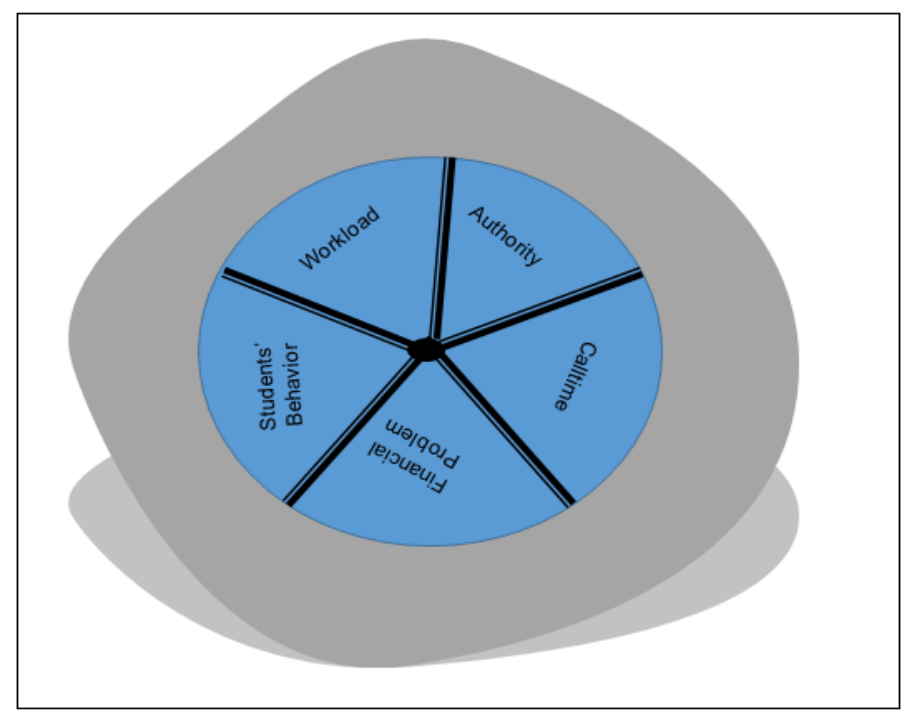

Figure 1: Practice Teachers' Flat Tire

The use of flat tire diagram is to represent the stressors of practice teachers. Just like a car having a flat tire, it cannot be expected to move forward to where it supposed to go unless it will be replaced and repaired. Similar case applies to the stressors of practice teachers if it will not be countered, it will hinder them to finish their teaching practice.

Studies of practice teachers' stress usually began with an investigation of the causes of the stress (Rieg et al., 2007). In this study, workload emerged as the number one stressor among the practice teachers. The study of Mapfumo et al., (2012) revealed that workload is one of the highest sources of stress among practice teachers. Murray-Harvey et al. (2000) found similar findings that submitting requirements are causing stress among Singaporean and Australian respondents on practice teaching. Based from the focused group discussion workload such as requirements is the top cause of their stress and this can be best supported by Kaur (2011) and Bhargava (2009 cited by Mapfumo et al., 2012) by concluding that one of the overwhelming stressors associated with course work was the work load. The respondents shared their experience through the focused group discussion and according to them having requirements while in the field of practicum is so stressful especially when they are simultaneously given. The examples of these requirements are plantilla, everyday lesson plan, instructional materials, field study manual and weekly journals. They also said that these became stressors to them because they do not know what to prioritize first. They also added that they really have to do their best in making their lesson plan to impress their cooperating teacher otherwise, they will be asked to redo it.

According to Kyriacou (2001) cited by Montgomery et al., (2005) confronting with the time pressure causes stress to practice teachers. It was supported by the study of Abebe (2001) who also found time management as stressful. The respondents talked about early call time which they need to adhere. The respondents mentioned that their call time is 7:15 in the morning. The call time caused them to be stressed because according to them, they have to finish their requirements up until dawn but they need to wake up early to prepare their teaching materials and they need time for personal grooming. The respondents claimed that time management becomes a stress to them because of the early call time wherein their brains cannot function well inside the classroom. They also said that they use their snack and lunch time to do other 
requirements and instructional materials. It becomes so stressful to them especially if they cannot manage their time properly.

Problems about financial expenses also came out as stressors from the study of Mapfumo et al., (2012). Based from the focus group discussion, respondents clearly stated why financial problem became a stressor to them. They said in the first place it is hard to find money for tuition fee and other expenses like the cost of their instructional materials, reproduced prints, and rent for the boarding house. They added that they tend to spend their food allowance just to suffice their school requirements which sometimes caused them to borrow money from their colleagues because they do not have enough budgets for their meals and transportation. They also mentioned that financial problem is not just their concern but to their parents as well because their parents need to send them allowance again.

Respondents also identified student misbehaviour as source of stress. Similar study conducted by Bezzina (2006), identified class discipline as the most challenging part of the teaching profession. According to her, most researches about students' actions are focused on students' misbehaviour. Tudela (2014) stated that in general, practice teachers' bad experiences are derived from failed lessons or difficulty managing student behaviour. Similar concern was identified by Atkinson (2004) stating that failure to overcome and manage students' behaviour might cause practice teachers to turn away from the teaching profession. Zeidner (1998) cited by Mapfumo et al., (2012) pointed out that disruptive learners create high stress among practice teachers. From the focus group discussion, respondents identified the misbehaviour that they observed in the classroom such as not listening to the practice teachers, roaming around, and getting low scores from the evaluations are the concerns of the respondents. These caused stress to the student teachers because according to them they feel like their teaching strategy is not enough.

People in authority also appeared to be one of the stressors of the practice teachers. In this study, the Cooperating Teacher and the Supervising Instructor are considered to be the people who are in the authority. One of the stressors of practice teachers identified by Kyriacou (2001, cited by Montgomery et al., 2005) was the relationships with the people in authority. She pointed out that to be evaluated inside the classroom causes panic and stress to practice teachers. Celik (2004) supported this by stating that the cooperating teacher and the teacher educator can act as sources of anxiety. Respondents reasoned out that they need to please their cooperating teacher because if they can't maintain a harmonious relationship with their cooperating teacher, teaching experience will not be enjoyable. The respondents also mentioned about the demands of the cooperating teacher such as to deliver the lessons well otherwise, practice teachers will redo their lessons. Respondents also noted why their Supervising Instructor causes stress to them because they do not help them in doing their lesson plans and practice teachers experiences fear because they have to impress them during their demo teaching.

\section{Effects of stressors}

\section{A. Negative effects}

Respondents identified the negative effects of stressors. These are lack of sleep, health problems, and no social life. According to Denise et al., (2013) sleep deprivation is a world-wide health concern. As stated by the respondents, they always encountered lack of sleep because some of them are working students; they also mentioned that they need to sacrifice their time in preparing lessons especially instructional materials that they use to effectively execute their lessons which is the reason why they only get two hours of sleep as their rest to prepare for tomorrows' another activity. They added also that lack of sleep also leads to health related 
concerns, such as acquiring the common colds easier, because the immune system becomes weak. They added that their body does not have enough time to recharge and regenerate lost energy. It was confirmed by Appold (2004) cited by Richard (2012) by stating that sleep deprivation may cause people to feel depressed and it affects the immune system. Kaur (2011) also supported this by identifying some effects of stress. Some of these are; increased blood pressure, cessation of digestive activities, and decrease in immune system's functions to preserve it for later action. He added that these may lead to the following serious and even fatal conditions: depression and anxiety, alcoholism and congenital heart diseases.

Although Knight et al., (2010) found out that a number of practice teachers indicated that they found support among their family and friends, the respondents in this study unfortunately identified deprivation of social life as one of the negative effects of stress. They mentioned that due to the stressors, they tend to spend more time to their academic responsibilities. They mentioned that they have no time for their family and friends and that their social life is being set aside.

\section{B. Positive effects}

There are two major positive effects raised by the practice teachers regarding the stressors. These are learning to budget their time and professionalism. It is interestingly noted that the stressors of practice teachers gave them reasons to get something positive that they applied in their practice teaching years. According to them, they learned to practice time management such as doing their requirements whenever they have vacant time to avoid cramming. By learning to budget their time, it prompted them to be punctual thus avoiding tardiness. Teachers are required to report for duty at least fifteen minutes before the start of lesson each day in order to prepare and to be ready to start work promptly (Alexander, 2003). The same call time applies to the practice teachers of Saint Louis University which requires them to come to school 15 minutes before the school time of the students. Some of the respondents shared their experiences that they are too lazy in doing their assigned task but when they adopted time management, they became responsible enough in attending school early and it benefitted them by doing their other requirements in advance. There are similar studies conducted which supports punctuality and time management as an important attitude that a teacher should possess. Ndifon \& Ukpepi (2014), teachers' punctuality to school is a vital factor or sub-variable of teacher's attitude to work, which can affect academic performance of pupils. They also mentioned teachers who are always punctual to school can instill such attitude in pupils, and this can result in good academic performance of the pupils. Hazaltine (1999) advised that teachers should bear in mind that being punctual is a part of showing courtesy which is a part of love, and a way people can express love and respect towards one another.

According to Isangedighi (1998), having professionalism avoids humiliation, rejection and worthlessness. The respondents mentioned that professionalism includes being responsible, and doing their task assigned to them properly. According to the respondents, if the requirements need to be passed within the same period of time, there is possibility that they cannot do the other requirements so they have to motivate themselves to be more responsible in doing their requirements to create quality output. They also added punctuality as one example of showing professionalism because according to them, teachers should not be getting late in coming to school because they emphasized that whatever the teacher shows in the class, learners may follow. 


\section{Coping mechanisms}

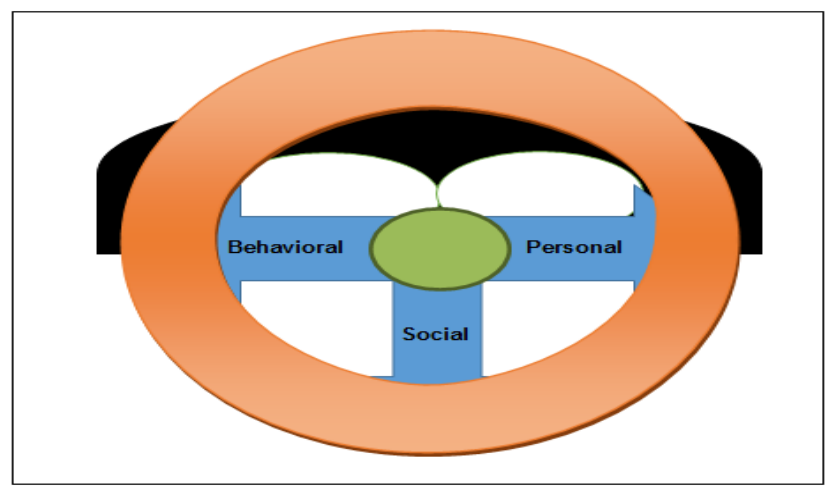

Figure 2: Practice Teachers' Steering Wheel

The practice teachers' steering wheel diagram shows the coping mechanisms of practice teachers. Just like a steering wheel, coping mechanisms serve as the guide and gives direction to the practice teachers to enable them to carry out practice teaching successfully.

The knowledge of knowing how practice teachers cope with stress is important to provide lecturers and administrators in teacher education programs in providing support for practice teachers (Murray-Harvey, 1999). It was supported by Morton et al., (1997 cited by Maapfumo et al., 2012) by suggesting that coping mechanisms on the part of the practice teachers could be enhanced if lecturers and administrators could identify the stressors of practice teachers and provide them support that they needed. Further, Bowers et al., (1983 cited by Mapfumo et al., 2012) encouraged administrators to pay more attention to the psychological readiness of practice teachers to cope with stress rather than concentrating on the teaching methodologies for their various subjects and disciplines. According to Murray-Harvey (2000), she categorized the coping mechanisms that practice teachers used to overcome their stressors. Some of these were:

\section{A. Personal coping strategies}

Some specific strategies were identified under the category of personal coping strategies include: (1) Cognitive strategies such as positive thinking, setting realistic expectations, blocking the negative, and included comments such as concentrating on the positive aspects more than the negative. This coping strategy talks about the right attitude of a practice teacher that they should be a positive thinker rather than thinking in a negative way because it could affect their performance, the way they appreciate themselves and there's a big possibility that their self-esteem will be affected and this is also known as being optimistic. Benard (1991) defined optimism as the sense of having positive future, to a tendency to find positive meaning in experiences, and a belief in one's ability to impact positively on one's environment and situation. He added that optimism has many benefits for mental health, including protecting against depression and anxiety. According to Bennis (2000), optimistic people have the gift of being able to convince others that they have the ability to achieve levels of performance beyond those they thought possible. Further, he stated that they move others from being stuck with how things are done and help them see how things could be done better. During the focus group discussion, practice teachers stated that thinking in a positive way is a blessing and they think positive all the time because if they think negatively, it could affect the way they teach. They also stated that they must always smile even if they feel irritated and stressed to have a positive outlook in life. Finally, they added that their family is one of the reasons why they feel motivated and optimistic because they always put in mind that the sacrifices of their parents will 
soon be worth all the hardships they experienced. (2) Ross et al. (2008) \& MurrayHarvey (1999) categorized eating habits and sleeping habits under behavioural coping strategies. Donna (2013), pointed out that it's perfectly acceptable to reward ourselves with a special treat, or to indulge in something savoury after a hard day. She mentioned that the two common reasons for emotional eating include stress and avoidance of negative emotions. According to her, stress increases the production of the stress hormone cortisol which makes us crave for foods that provide a good feeling and energy. Practice teachers reasoned out that after a long period of time in school, they go to the school canteen to relieve stress by eating. They regarded eating as a way of socializing with other colleagues because they can talk to each other and they can share their problems that had happened during the day.

According to Trockel (2009), it was noticed that students experiencing sleep deprivation try to avoid more difficult tasks. Also, they often are not aware that the difficulties they are having academically can be directly related to their poor sleep quality as noted by Engle-Friedman (2003). It is beneficial to get an adequate amount of sleep each night to give clear thinking and strength to deal with life's daily stresses (BSC 2009 cited by Richards, 2012). It is amazingly noted that despite the emergence of sleep deprivation as one of the sources of stress among the respondents, practice teachers are still eager to find time to sleep. Based from the focus group discussion, they find time to cope with their stressor by sleeping during their break time. They added that lack of sleep can be avoided by doing their requirements ahead of time so that they can sleep early. They also mentioned that they really need to get enough sleep in order for them to have energy to teach for the next day.

\section{B. Social coping strategies}

Turning to family and friends in times of crisis or simply for conversation and reflection was widely reported as a significant coping strategy (MacDonald, 1993 cited by Mapfumo et al., 2012). Done (2006) encouraged cracking jokes with colleagues to lessen the effect of stress and this could also be beneficial in teaching the class. During the focus group discussion, practice teachers mentioned that communicating with their colleagues and cracking jokes are some ways on which they can forget their problems for a while. In addition, establishing rapport with their co practice teachers and cooperating teachers can help them forget the problems they had encountered during the day.

\section{Conclusion}

Based from the findings of this study, practice teachers are not excused from experiencing the effects of stress. It can be concluded that practice teaching is one of the most challenging parts in the life of every educator. This study shows that even if practice teachers are facing a lot of stressors, they still find ways to seek solutions to meet these challenges by applying coping mechanisms such as treating the stressors as motivations for them to become more responsible. Recommendations can also be drawn from the findings such as providing lectures and forum to incoming practice teachers regarding the stressors and coping mechanisms that they might be encountering soon in the field of teaching to give them strategies on how they could combat the different stressors. Supervising instructors and cooperating teachers must also be advised to provide support for practice teachers in helping them overcome the stressors along with helping them in giving teaching strategies and methodologies in carrying out certain subjects. It is also the recommendation of this research to suggest future researchers who are interested to conduct the same study to consider the demographics and specialization of practice teachers to further gather intensive and extensive information about stressors and coping mechanisms of both male and female practice teachers in the different specialization of the teaching profession. 


\section{References}

[1] Abebe, S., \& Haile Mariam, A. (2011). Teacher stressors and potential remedies from pre-service teachers' and cooperating Teachers' Perspectives. Eastern Education Journal, 40(1), 64-74.

[2] Afandi, O., Hawi, H., Mohammed, L., Salim, F., Hameed, A. K., Shaikh, R. B., \& Khan, F. A. (2013). Sleep Quality Among University Students: Evaluating the Impact of Smoking, Social Media Use, and Energy Drink Consumption on Sleep Quality and Anxiety. Student Pulse, 5(06).

[3] Bezzina, C. (2006). Views from the trenches: Beginning teachers' perceptions about their professional development. Journal of In-Service Education, 32(4), 411430.

[4] Bland, H. W., Melton, B. F., Welle, P., \& Bigham, L. (2012). Stress tolerance: New challenges for millennial college students. College Student Journal, 46(2), 362.

[5] Chaplain, R. P. (2008). Stress and psychological distress among trainee secondary teachers in England. Educational Psychology, 28(2), 195-209.

[6] Charlesworth, R., Hart, C. H., Burts, D. C., Thomasson, R. H., Mosley, J., \& Fleege, P. O. (1993). Measuring the developmental appropriateness of kindergarten teachers' beliefs and practices. Early Childhood Research Quarterly, 8(3), 255-276.

[7] Chong, S. N. Y., Wong, I. Y. F., \& Quek, C. L. (2005). Pre-service teachers ${ }^{\mathrm{TM}}$ beliefs, attitudes and expectations: a review of the literature.

[8] Deniz, M. (2006). The relationships among coping with stress, life satisfaction, decision-making styles and decision self-esteem: An investigation with Turkish university students. Social Behavior and Personality: an international journal, 34(9), 1161-1170.

[9] Done, P. (2006). Make'em Laugh (\& They'll Learn a Lot More). Instructor, 115(7), 32-34.

[10] Ekpenyong, C. E., Daniel, N. E., \& Aribo, E. O. (2013). Associations between academic stressors, reaction to stress, coping strategies and musculoskeletal disorders among college students. Ethiopian journal of health sciences, 23(2), 98-112.

[11] Engle-Friedman, M., Riela, S., Golan, R., Ventuneac, A. M., Davis, C. M., Jefferson, A. D., \& Major, D. (2003). The effect of sleep loss on next day effort. Journal of sleep research, 12(2), 113-124.

[12] Gerges, G. (2001). Factors Influencing Preservice Teachers' Variation in Use of Instructional Methods: Why Is Teacher Efficacy Not a Significant Contributor? Teacher Education Quarterly, 71-88.

[13] Gray, E. K., \& Watson, D. (2002). General and specific traits of personality and their relation to sleep and academic performance. Journal of Personality, 70(2), 177206.

[14] Isangedighi, A. J. (1998). A climpse of teacher commitment. The Journal of Research in Curriculum Studies, 1(1), 65-73.

[15] Kaur, S. (2011). Comparative Study of occupational Stress among Teachers of private and Government Schools in Relation to their Age, Gender, and Teaching Experience. International Journal of Educational Planning and Administration. 1:2:151-160.

[16] Kiggundu, E., \& Nayimuli, S. (2009). Teaching practice: a make or break phase for student teachers. South African Journal of Education, 29(3), 345-358.

[17] Knight, C., Balatti, J., Haase, M., \& Henderson, L. (2010). Preservice teacher stressors and their reactions to those stressors: Resilient responses.

[18] Kyriacou, C., \& Kunc, R. (2007). Beginning teachers' expectations of teaching. Teaching and Teacher Education, 23(8), 1246-1257.

[19] Lazarus, R. S., \& Folkman, S. (1987). Transactional theory and research on emotions and coping. European Journal of personality, 1(3), 141-169. 
South American Journal of Academic Research

Volume 3, Issue 1, 2016

[20] MacDonald, C. J. (1993). Coping with stress during the teaching practicum: The student teacher's perspective. Alberta Journal of Educational Research.

[21] Mapfumo, J. S., Chitsiko, N., \& Chireshe, R. (2012). Teaching Practice generated stressors and coping mechanisms among student teachers in Zimbabwe. South African Journal of Education, 32(2), 155-166.

[22] Montgomery, Cameron, and André A. Rupp. "A meta-analysis for exploring the diverse causes and effects of stress in teachers." Canadian Journal of Education/Revue canadienne de l'éducation (2005): 458-486.

[23] Murray-Harvey, R. (1999). How teacher education students cope with practicum concerns. The Teacher Educator, 37(2), 117-132.

[24] Ndifon, R. A., \& Cornelius-Ukpepi, B. U. (2014). The Relationship between Primary School Teacher's Attitude to Work and Pupils' Academic Performance in Cross River State, Nigeria. British Journal of Arts \& Social Sciences, 17(2).

[25] Ngidi DP \& Sibaya PT 2003. Student teacher anxieties related to practice teaching. South African Journal of Education, 23:18-22.

[26] Oral, B. (2012). Student Teachers' Classroom Management Anxiety: A Study on Behavior Management and Teaching Management. Journal of Applied Social Psychology, 42(12), 2901-2916.

[27] Paulhus, D. L., \& Martin, C. L. (1988). Functional flexibility: A new conception of interpersonal flexibility. Journal of personality and social psychology, 55(1), 88.

[28] Powers, G. T. (2002). Toward a resilience-based model of school social work: A turnaround mentor. Resiliency: An integrated approach to practice, policy, and research, 153-170

[29] Richards, J. (2012). Teacher stress and coping strategies: A national snapshot. The educational forum, vol.76

[30] Rieg, S. A., Paquette, K. R., \& Chen, Y. (2007). Coping with stress: An investigation of novice teachers' stressors in the elementary classroom. EDUCATIONINDIANAPOLIS THEN CHULA VISTA-, 128(2), 211.

[31] Samms, C. L. (2010). Relationship Between Dissimilar Cognitive Styles, Use of Coping Behavior and Use of Learning Strategies (Doctoral dissertation, New Jersey Institute of Technology)

[32] Sanyal Tudela, A. (2014). Discourses of Experience: The Disciplining of Identities and Practices in Student Teaching. Australian Journal of Teacher Education, 39(3), n3.

[33] Schempp, P. G. (1995). Learning on the job: An analysis of the acquisition of a teacher's knowledge. Journal of Research and Development in Education, 28(4), 237244.

[34] Üstün, B. T., \& Jakob, R. (2005). Calling a spade a spade: meaningful definitions of health conditions. Bulletin of the World Health Organization, 83(11), 802-802.

[35] Wadlington, E. M., Slaton, E., \& Partridge, M. E. (1998). Alleviating stress in pre-service teachers during field experiences. Education, 119(2), 335. 